\title{
Heat-resistant Properties in Autoclaving of New Polycarbonate Bottles Containing a Disinfectant of Chlorhexidine Digluconate Solution
}

\author{
YoSHIYUKI KAGAWA ${ }^{* 1}$, SHOJI INAGAKI ${ }^{\dagger 1}$, HIDESHI KAKITO ${ }^{\dagger 1}$, \\ YOSHINOBU KOBAYASHI ${ }^{\dagger 2}$ and MichIO KoJIMA ${ }^{\dagger 1}$
}

Department of Hospital Pharmacy, Mie University School of Medicine ${ }^{\text {t1 }}$ Tokyo Umano Kagaku Co. Ltd. ${ }^{\dagger 2}$

\author{
$\left(\begin{array}{l}\text { Received December 15, 1993 } \\ \text { Accepted June 20, 1994 }\end{array}\right)$
}

\begin{abstract}
Heat-resistant polycarbonate bottles were newly devised for autoclave sterilization of chlorhexidine digluconate solution, a disinfectant. To assess the usefulness in the clinical application, the shape transformation of the bottles and the chemical stability of their content of $0.05 \%$ chlorhexidine digluconate solution were examined after autoclaving in comparison with those of glass bottles and of their contents. The auioclaving experiment was performed at $115^{\circ} \mathrm{C}$ for 30 minutes. After autoclaving, the polycarbonate bottles increased slightly of less than $1.62 \%$ in outer diameter, whereas the change with glass bottles was unmeasurable. Levels of chlorhexidine digluconate and p-chloroaniline, its decomposition product, were determined in both types of bottles by high-performance liquid chromatography at 1 day and 1,3, and 6 months after autoclaving. Levels of chlorhexidine digluconate remaining until 6 months after autoclaving were more than $98 \%$ and $97 \%$ in the polycarbonate and glass bottles, respectively. p-Chloroaniline was generated after autoclaving in levels of $0.02-0.90 \mu \mathrm{g} / \mathrm{ml}$ in the polycarbonate bottles and of $0.06-0.90$ $\mu \mathrm{g} / \mathrm{ml}$ in the glass bottles throughout the study. These results suggest that the newly devised polycarbonate bottles are resistant to heat and mechanical shocks, and that they are as useful as the presently used glass bottles for sterilizing and storing the chlorhexidine digluconate solution.
\end{abstract}

Keywords - polycarbonate bottle, chlorhexidine digluconate, autoclaving, p-chloroaniline, shape transformation, chemical stability

\section{Introduction}

Chlorhexidine is a potent bactericide synthesized by Davies et al. ${ }^{1)}$ in 1954 . Chlorhexidine digluconate is a water soluble type of chlorhexidine and is widely used as a disinfectant in hospitals. The sterilizing effect of chlorhexidine is extremely strong against the majority of vegetative bacteria, but not against spores and virus.

Attention has recently been drawn to a fact that gramnegative bacteria, chiefly Pseudomonas fluorescens and non-pigmented Pseudomonas species, could survive in spite of the presence of chlorhexidine ${ }^{2}$. This fact means that chlorhexidine solutions should be prepared in a way ensuring a

t1 三重県津市江戸橋2-174; 2-174, Edobashi, Tsu-shi, Mie, 514 Japan

t2 東京都文京区本郷4丁目29-18; 4-29-18, Hongou, Bunkyou-ku, Tokyo, 112 Japan 
high degree of sterility, e.g., by autoclaving. When the chlorhexidine solutions are autoclaved, it is necessary to take into account a possibility of decomposition of chlorhexidine to p-chloroaniline. Further, Dolby et al. ${ }^{3)}$ reported that p-chloroaniline was contaminated in chlorhexidine solution with a concentration of $265 \mathrm{ppm}$ even before autoclaving.

Several kinds of sterilizing bottles made from plastics have been developed. Existing plastic bottles are inferior to glass bottles in lower heat-stability and lower light-permeability, even though the plastic bottles are lighter in weight and more resistant to mechanical shocks than the glass bottles. Therefore, a new type of plastic bottles which improve these problems has been desired. We newly devised polycarbonate bottles suitable for sterilizing and storing chlorhexidine digluconate solution.

The objective of this study was to evaluate the usefulness of these bottles in clinical use, i.e., to determine shape transformation of the polycarbonate bottles and stability of their content of chlorhexidine digluconate solutions after autoclaving.

\section{Materials and Methods}

Chemicals. Chlorhexidine digluconate as $20 \%(\mathrm{w} / \mathrm{v})$ solution (lot PU628), $5 \%(\mathrm{w} / \mathrm{v})$ solution of chlorhexidine digluconate (Hibitane ${ }^{\star}$, lot SE235) and $20 \%(\mathrm{w} / \mathrm{v})$ solution of chlorhexidine digluconate (Hibitane ${ }^{\star}$ gluconate, lot PU628) were purchased from ZENECA (Macclesfield, England). p-Chloroaniline was purchased from Wako Pure Chemical Industries (Osaka, Japan, lot PDE 1037). All other reagents used were of analytical grade and used without further purification.

Sterilizing bottles. Polycarbonate bottles (Tokyo Umano Kagaku Co., Tokyo, Japan) and glass bottles (Giyaman Co., Tokyo, Japan) as control were used in this study. The polycarbonate bottles have curved portions on both sides of their bodies (see Fig. 1) to be grasped easier by hand. The polycarbonate bottles were passed the plastic container test for aqueous infusion prescribed in Japanese Pharmacopoeia XII.

Autoclaving Treatment. Autoclaving experiment was performed in an automatic steam autoclave (Sakura Seiki Co., Tokyo, Japan, Model Y-O06SLPCZ). Autoclaving condition was described in Fig. 2. This apparatus has a pressure-control system to minimize a pressure difference between the inner and outer sides of the plastic bottles. This system can prevent those bottles from breaking down caused by the pressure difference. Autoclaving was done at $115 \pm 0.5^{\circ} \mathrm{C}$ for 30 minutes according to the method described in the Japanese Pharmacopoeia XII. After the sterilizing time of 30 minutes, temperature of the bottles was gradually cooled down by spraying water on them.

Shape Transformation of Bottles. The polycarbonate and glass bottles were filled with 500 $\mathrm{ml}$ of $0.05 \%$ chlorhexidine digluconate solution. Before and after autoclaving, a shape transformation rate of the outer diameter of the polycarbonate and glass bottles was determined by measuring the narrowest and widest diameters as indicated in Fig. 1. As another index of the shape transformation, changes in a liquid volume were measured for each bottle before and after autoclaving.

Storage Conditions for Bottles after Autoclaving. After autoclaving, all bottles containing chlorhexidine digluconate solution were stocked for up to 6 months in a room (12 h-light and $12 \mathrm{~h}$ dark cycle) at room temperature $\left(20\right.$ to $\left.25^{\circ} \mathrm{C}\right)$. 


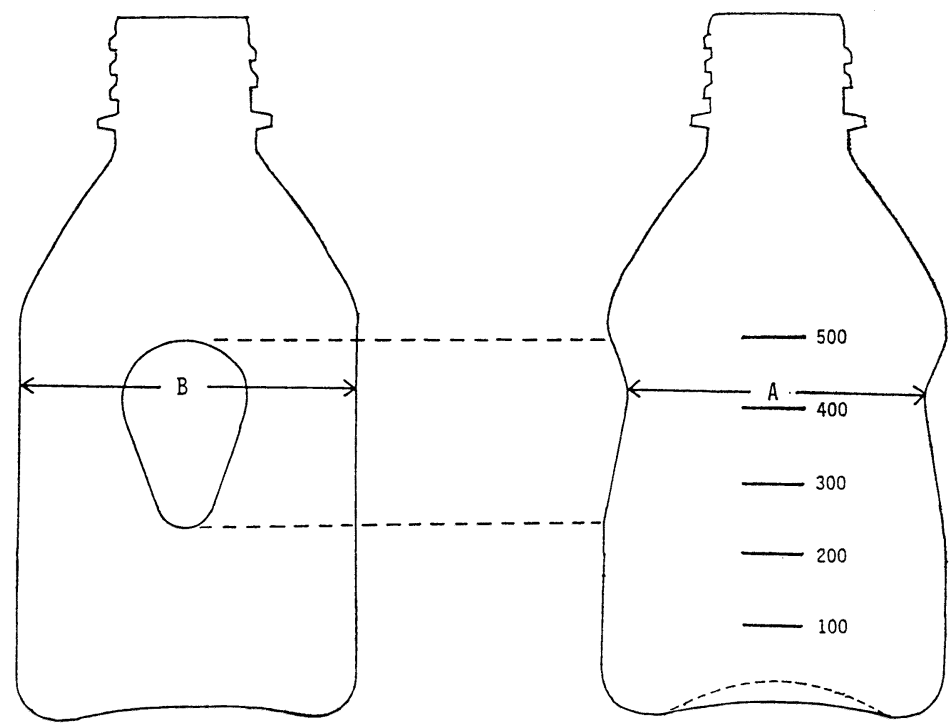

Fig. 1. An Outward Form of the Polycarbonate Bottle $(500 \mathrm{ml})$

" $A$ " and " $B$ " indicate the narrowest and widest diameters, respectively. A part of eggplant shape in the left figure corresponds to a concaved part of the bottle in the right figure.
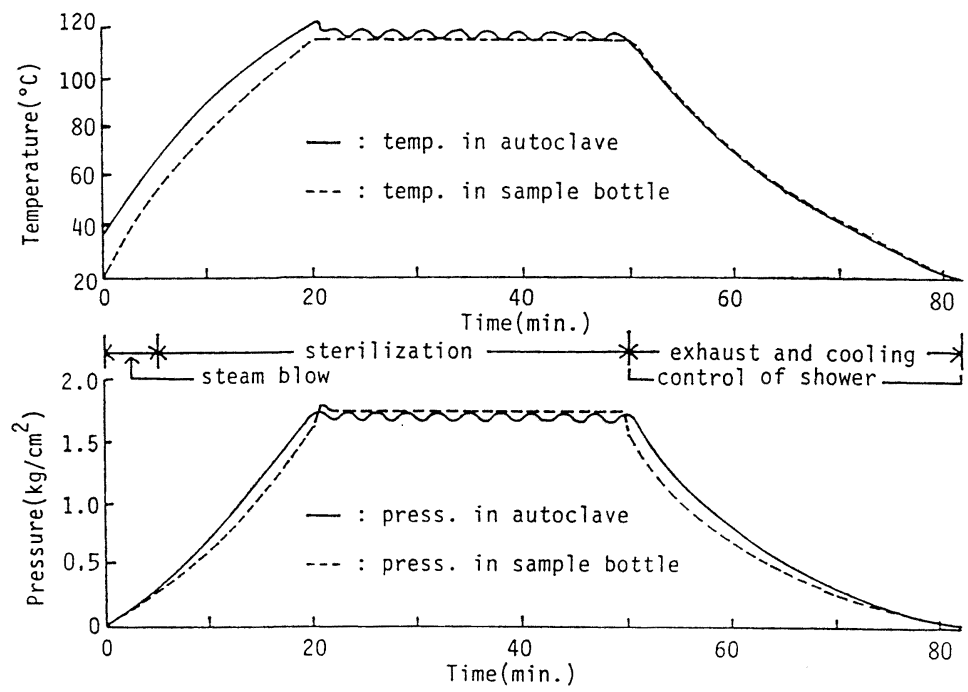

Fig. 2. Autoclaving Condition of the Polycarbonate and Glass Bottles at $115^{\circ} \mathrm{C}$ for 30 minutes using Sakura Sterilizer (Y-O006SLPCZ)

Continuous and broken lines show changes in temperature (the upper) and pressure (the lower) in an autoclave and in a sample bottle, respectively, as a function of time. The apparatus has a pressure-control system to minimize a pressure difference between the inner and outer sides of a sterilizing bottle. This system can prevent the bottles from breaking caused by the pressure difference. 
Assay Apparatus. Samples withdrawn from the bottles were analyzed by a high performance liquid chromatography (HPLC) method. An HPLC pump (Waters Associates, Milford, MA, Model 510) was connected to an autoinjector (Waters, Model 712), a multiple-wavelength ultraviolet light detector (Waters, model 490), and a data and chromatography control station (Waters, Model 840). A $\mathrm{C}_{18}$ column ( $\mu$ Bondapak $\mathrm{C}_{18}, 30 \mathrm{~cm} \times 3.9 \mathrm{~mm}$, Waters) was maintained at $40^{\circ} \mathrm{C}$ with a column heater (Waters).

HPLC Assay. The mobile phase was prepared by adding $20 \mathrm{ml}$ of $0.25 \%$ solution of 1 -pentane sulphonic acid (Tokyo Kasei, Tokyo, Japan, lot FCY01) in gracial acetic acid and $5 \mathrm{ml}$ of triethylamine (Wako Pure Chemical Industries Ltd., Osaka, Japan lot KPQ0401) to $350 \mathrm{ml}$ of acetonitrile to making up to $1000 \mathrm{ml}$ with water ${ }^{4}$. The solution was then adjusted to $\mathrm{pH} 3.0$ with phosphoric acid and degassed by vacuum. The flow rate was $1.0 \mathrm{ml} / \mathrm{min}$, and the wavelength was set at $254 \mathrm{~nm}$. Each chromatogram was obtained from a $10 \mu \mathrm{l}$ injection volume of the samples. Decrease in the chlorhexidine digluconate concentration was calculated as percentage change in mean peak area for each sample compared with the mean peak area before autoclaving.

Statistical Analysis. Data are expressed as means \pm S.D. A one-way analysis of variance (ANOWA) and Dunnett's test were used for comparison among the means of different groups ${ }^{5}$. A p value of $<0.05$ was considered statistically significant.

\section{Results}

Shape Transformation of Bottles. Heat-resistant properties of the polycarbonate bottles were examined for their shape transformation. The polycarbonate bottles as well as the glass bottles were filled with $500 \mathrm{ml}$ of either Solution A $\left(0.05 \%\right.$ Hibitane ${ }^{\star}$ solution), Solution B $(0.05 \%$ Hibitane gluconate solution) or distilled water. These bottles were autoclaved at $115^{\circ} \mathrm{C}$ for $30 \mathrm{~min}$. Table 1 (the left side) shows shape transformation rates of the polycarbonate bottles after autoclaving. Increasing rates (\%) after autoclaving in a diameter measured at the narrowest part were $1.00-1.61 \%$ larger than those of a diameter measured at the widest part. The rates were however so small that the shape transformation of the bottles after autoclaving was apparently disregarded.

Table 1 (the right side) also shows increasing rates of both a total volume and a scale mark volume of the polycarbonate bottles after autoclaving. The total volume indicates a volume of water that needs to overflow the bottle. The scale mark volume indicates a volume of water that needs to reach the notched line of $500 \mathrm{ml}$. The liquid volumes, presented as the total volume and the scale mark volume, were changed by less than $2 \%$ in all cases.

Chlorhexidine Digluconate Concentrations before and after Autoclaving. To examine the stability of chlorhexidine digluconate in the polycarbonate and glass bottles, remaining concentrations of chlorhexidine digluconate and its decomposition product, p-chloroaniline, in the bottles was determined by HPLC before and after autoclaving. Coefficients of variation (CV) of the standard solutions containing chlorhexidine digluconate of 1.95 to $500 \mu \mathrm{g} / \mathrm{ml}$ were under $2.9 \%$, and those of standard solutions containing p-chloroaniline of 0.04 to $2.50 \mu \mathrm{g} / \mathrm{ml}$ were under $10 \%$.

Table 2 shows the remaining concentrations of chlorhexidine digluconate in the Solution $A$ and 
Table 1. Shape Transformation Rates of Polycarbonate Bottles after Autoclaving

\begin{tabular}{lccccc}
\hline \multirow{2}{*}{ Contents } & \multicolumn{2}{c}{$\begin{array}{c}\text { Increasing rate of outer } \\
\text { diameter (\%) }\end{array}$} & & \multicolumn{2}{c}{ Increasing rate of liquid volume (\%) } \\
\cline { 2 - 3 } & Narrowest & Widest & & Total volume & Scale mark (500 ml) \\
\hline $\left.\begin{array}{l}\text { Solution A } \\
(0.05 \% \text { Hibitane }\end{array}\right)$ & $1.54 \pm 0.22$ & $0.10 \pm 0.11$ & & $0.83 \pm 0.16$ & $1.08 \pm 0.28$ \\
$\begin{array}{l}\text { Solution B } \\
(0.05 \% \text { Hibitane }\end{array}$ & $1.25 \pm 0.38$ & $0.25 \pm 0.22$ & & $0.39 \pm 0.23$ & $0.36 \pm 0.59$ \\
Distilled Water & $1.62 \pm 0.44$ & $0.01 \pm 0.21$ & & $0.97 \pm 0.18$ & $1.21 \pm 0.42$ \\
\hline
\end{tabular}

Autoclaving experiments were performed at $115^{\circ} \mathrm{C}$ for $30 \mathrm{~min}$. An increasing rate of each index after autoclaving was calculated by comparing the values measured before and after autoclaving. Values are means \pm S.D. of 10 experiments and statistically analyzed by Dunnett's test.

Table 2. Stability of $0.05 \%$ Chlorhexidine Digluconate Solutions in Polycarbonate and Glass Bottles after Autoclaving

\begin{tabular}{|c|c|c|c|c|c|}
\hline & & \multicolumn{4}{|c|}{ Remaining \% of Chlorhexidine Digluconate } \\
\hline & & \multicolumn{4}{|c|}{ Time after Autoclaving } \\
\hline & & 1 day & 1 month & 3 months & 6 months \\
\hline Contents & Bottles & & & & \\
\hline Solution A & Polycarbonate & $99.73 \pm 0.54$ & $99.38 \pm 0.45$ & $\left.99.54 \pm 0.79^{a}\right)$ & $99.10 \pm 0.18^{\mathrm{b}}$ \\
\hline$\left(0.05 \%\right.$ Hibitane $\left.^{\oplus}\right)$ & Glass & $99.38 \pm 0.71$ & $98.98 \pm 0.15$ & $98.16 \pm 0.98$ & $97.85 \pm 0.18$ \\
\hline Solution B & Polycarbonate & $99.90 \pm 0.93$ & $99.24 \pm 0.63$ & $98.70 \pm 0.40$ & $99.51 \pm 0.71^{\mathrm{b})}$ \\
\hline $\begin{array}{l}\text { (0.05\% Hibitane } \\
\text { gluconate) }\end{array}$ & Glass & $98.90 \pm 0.64$ & $99.07 \pm 0.41$ & $97.88 \pm 0.35^{\mathrm{c})}$ & $98.24 \pm 0.88$ \\
\hline
\end{tabular}

Autoclaving experiments were performed at $115^{\circ} \mathrm{C}$ for $30 \mathrm{~min}$. The bottles containing the disinfectant solutions after autoclaving were stored in a room (12 h-light and $12 \mathrm{~h}$-dark cycle) at room temperature. The caps of the bottles were remained to be tightened till the day of analysis. The remaining percentage of chlorhexidine digluconate was calculated by comparing the actual concentrations determined before and after autoclaving. Values are means \pm S.D. of 5 to 6 experiments and statistically analyzed by Dunnett's test.

a) Significantly different from the value for the glass bottles $(p<0.05)$.

b) Significantly different from the value for the glass bottles $(\mathrm{p}<0.01)$.

c) Significantly different from the value before autoclaving $(\mathrm{p}<0.01)$.

the Solution B at 1 day, and 1, 3, 6 months after autoclaving. In all cases during 6 months after autoclaving, the remaining of chlorhexidine digluconate was more than $97.85 \%$. In the case of the Solution A, the polycarbonate bottles had $0.25-0.40 \%$ higher remaining of chlorhexidine digluconate than the glass bottles had (Table 2). In the case of the Solution $B$, the remaining of chlorhexidine digluconate was $0.17-1.27 \%$ higher in the polycarbonate bottles than in the glass bottles.

Table 3 indicates p-chloroaniline concentrations formed in the Solution A and the Solution B before and 1 day to 6 months after autoclaving. Before autoclaving, 0.10 to $0.22 \mu \mathrm{g} / \mathrm{ml} \mathrm{p}$-chloroaniline was already involved in both solutions. In the case of the Solution A, the p-chloroaniline concentration increased with time after autoclaving, i.e., reached a peak at 1 month and then decreased gradually to 
Table 3. p-Chloroaniline Formation from $0.05 \%$ Chlorhexidine Digluconate Solutions in Polycarbonate and Glass Bottles after Autoclaving

\begin{tabular}{|c|c|c|c|c|c|}
\hline & & \multicolumn{4}{|c|}{$\mathrm{p}$-Chloroaniline concentration $(\mu \mathrm{g} / \mathrm{ml})$} \\
\hline & & \multicolumn{4}{|c|}{ Time after autoclaving } \\
\hline & & Before & 1 day & 1 month & 6 months \\
\hline Contents & Bottles & & & & \\
\hline Solution A & Polycarbonate & $0.13 \pm 0.03$ & $0.46 \pm 0.06$ & $0.66 \pm 0.05$ & $0.08 \pm 0.03$ \\
\hline$\left(0.05 \%\right.$ Hibitane $\left.{ }^{\circledast}\right)$ & Glass & $0.10 \pm 0.04$ & $0.37 \pm 0.07$ & $0.68 \pm 0.05$ & $0.06 \pm 0.02$ \\
\hline Solution B & Polycarbonate & $0.18 \pm 0.04$ & $0.90 \pm 0.06$ & $0.34 \pm 0.03^{a)}$ & $0.02 \pm 0.01^{a)}$ \\
\hline $\begin{array}{l}(0.05 \% \text { Hibitane } \\
\text { gluconate) }\end{array}$ & Glass & $0.22 \pm 0.04$ & $0.90 \pm 0.05$ & $0.62 \pm 0.07$ & $0.16 \pm 0.04$ \\
\hline
\end{tabular}

Autoclaving experiments were performed at $115^{\circ} \mathrm{C}$ for $30 \mathrm{~min}$. The bottles containing the disinfectant solutions were stored in a room ( $12 \mathrm{~h}$-light and $12 \mathrm{~h}$-dark cycle) at room temperature after autoclaving. The caps were remained to be tightened till the day of examination. Values are means \pm S.D. of 5 to 6 experiments and statistically analyzed by Dunnett's test.

a) Significantly different from the value for the glass bottles $(\mathrm{p}<0.01)$.

its original level by 6 months. In the case of the Solution B, however, a maximum level of pchloroaniline was attained immediately after autoclaving and declined slowly to its original level by 6 months. A maximum concentration was obtained at 1 month in both bottles filled with the Solution A and at 1 day in both bottles filled with the Solution $B$. These results indicate that there is no difference in p-chloroaniline formation from the Solution A and the Solution B between the polycarbonate and glass bottles after autoclaving.

\section{Discussion}

Polypropylene bottles are most commonly used for autoclaving. Comparing with glass bottles, the polypropylene bottles have disadvantages in light-permeable and heat-stable properties. However, the polypropylene bottles are resistant to mechanical shocks and their lower lightpermeability has an advantage in protecting their contents from light exposure. The bottles made from polypropylene greatly transform in their shape by autoclaving.

We newly devised a new type of the polycarbonate bottles that are colorless and lightpermeable as are the glass bottles. To evaluate a practical usefulness of the polycarbonate bottles in autoclaving, a shape transformation of the bottles and a stability of chlorhexidine digluconate solution in the bottles were examined after autoclaving. The shape transformation rate after autoclaving was less than $1.7 \%$, indicating no apparent change in the shape transformation. Kawahara et al. ${ }^{6}$, however, reported that transformation rate of polypropylene bottles was about $8 \%$. The present results indicate that this bottle can well tolerate in autoclaving at $115^{\circ} \mathrm{C}$ for $30 \mathrm{~min}$.

The stability of chlorhexidine digluconate was studied in the polycarbonate bottles after autoclaving. Chlorhexidine digluconate was reported to degrade to p-chloroaniline in parallel with a rise of temperature and pressure in autoclaving ${ }^{3,7}$. The HPLC analysis of chlorhexidine digluconate 
and p-chloroaniline showed a good separation in their peaks and low CV values of both agents, indicating a reliability of an analysis. The remaining percentages of chlorhexidine digluconate in the polycarbonate bottles were essentially equal to those in the glass bottles at any time examined. The light-permeability of the polycarbonate bottles did not damage the stability of chlorhexidine digluconate. These results confirm that the polycarbonate bottles are useful for the sterilization by autoclaving and for the storage of chlorhexidine digluconate, as well as the glass bottles. Amounts of p-chloroaniline produced immediately after autoclaving in the present both bottles were lower than those reported previously for the glass bottles ${ }^{3}$. This difference for the production of p-chloroaniline may come from a fact that a time to reach at the sterilizing temperature and pressure was different between the present and previously reported experiments. Differences of production levels and peak times between the Solution A and the Solution B was found. Reasons for these differences are not clear. But $\mathrm{pH}$ values of these solutions may be responsible for its difference, namely $\mathrm{pH}$ values of Solution A and Solution B before autoclaving was 5.36 and 6.09, respectively. Until 6 months after autoclaving, $\mathrm{pH}$ values were constant and did not found significant difference in two kinds of bottles. These bottles are also useful for sterilizing distilled water.

\section{References}

1) G. E. Davies, J. Francis, A. R. Martin, F. L. Rose and G. Swain, Br. J. Pharmacol, 9, 192-196 (1954).

2) D. W. Burdon and J. I. Whitby, Bri. Med. J., 2, 153-155 (1967).

3) J. Dolby, B. Gunnarsson, L. Kronberg and H. Wikner, Pharm. Acta Helv., 47, 615-620 (1972).

4) R. L. Perez, J. Chromatogr. Sci., 19, 570-572 (1981).

5) S. Wallenstein, C. L. Zucker and J. L. Fleiss, Circ. Res., 47, 1-9 (1980).

6) M. Kawahara, M. Asahi, T. Komai, F. Ichimura, K. Yamamori, S. Okawa and I. Arai, Jpn. J. Hosp. Pharm., 13, 391-395 (1987).

7) R. R. Goodall, J. Goldman and J. Woods, Pharmaceutical J., 200, 33-34 (1968). 